In finally summarising the position of evening education in London, Mr. Blair concludes with the following passage (p. 24):--"A large increase of students in higher institutions, a large extension of premises and improved equipment, a large increase all over in attendance hours per student . . . an increased representation of masters and workmen on advisory committees, with a corresponding increase in the interest of employers, and of expert criticism of work done, all support the view that the period 1904-12 has been characterised by great expansion in quantity and quality of work."

Since the publication of the report referred to above the education committee of the council has decided upon a comprehensive scheme of reorganisation of the evening continuation schools, which are in future to be termed "institutes" instead of "schools." The main features of the scheme are the specialisation of the functions of individual schools depending upon the social, educational, and industrial demands of the respective districts, the appointment of a number of "responsible masters" for evening work only, the increased provision of non-vocational education, and definite coordination with higher institutions, such as the polytechnics. It is mainly in respect to the last point that the organisation of London evening education has compared very unfavourably of recent years with the organisation in a number of provincial towns.

The junior technical institutes will be definitely linked up in future with the neighbouring polytechnic. The principal (or head of department) of the higher institution will have the right to visit the junior institute in an advisory capacity, and to offer advice upon the appointment of the staff and upon the framing of courses and syllabuses. Standing local committees will be formed consisting of the principal and heads of departments of the polytechnic and "responsible masters" of the junior institutes, in order to cement the relationship between the two types of institutions.

The new scheme as a whole is thoroughly sound, and, if carried out, as there is every reason to expect will be the case, it will undoubtedly have far-reaching, beneficial effects upon London education.

\section{J. WILSON.}

\section{LAW OF THE PAY-STREAK IN PLACER DEPOSITS. ${ }^{1}$}

F XPLANATIONS of the eccentricities of the payF streak in placer deposits have long been considered difficult to furnish. Geikie, Beck, Posepny, Locke, Lindgren, and many others have all discussed the subject and acknowledged the fact. Eight years' residence and study of placer phenomena in the Klondike gold-bearing region of Canada on the part of Mr. J. B. Tyrrell have enabled him to formulate a natural law respecting the location of the paystreak, not only in the Klondike, but also in any placer region of the world.

An accurate knowledge of the structure and growth of a valley, comprising the different phases of its history in detail, always presents geological facts and deductions capable of broad and general application, and these are generally recognisable without great difficulty. After considering the nature and rate of erosion and sedimentation in a given valley under normal stream action, the formation of a V-shaped valley and its transformation into a U-shaped one, and the presence of flood-plains and terraces, the laws

1 "The Laws of the Pay-streak in Placer Deposits." By J. B. Tyrrell. Trans. Inst. Min. and Metallurgy, pp. 593-605. (London, rgra.) NO. 2272 , VOI. $9 \mathrm{I}]$ governing the formation and position of the pay-streak in an alluvial plain in the bottom of a valley may be stated as follows :-

(x) It was formed in the bottom and at the mouth of the V-shaped valley which was the young representative of the present valley.

(2) It marks the position formerly occupied by the bottom of that V-shaped valley.

(3) The gold contained in it was washed out of the surrounding country and collected into approximately its present position before the gravel of the floodplain (or terrace) was deposited over and around it.

The practical application of this discovery of identifying nature's way of hydraulicing and storing the gold in the bottoms of the valleys must be welcome to all economic geologists and mining engineers.

Mr. Tyrrell holds that some $30,000,000 l$. of gold has been recovered to date from the Klondike region, and that an equal amount no doubt remains to be ex. tracted. Some $900 \mathrm{ft}$. thick of rock-formations have been removed from the Klondike country, and 130 cubic miles of gravel scattered over the 800 square miles of placer deposits, making only one-hundredth of a pennyworth of gold per ton of original rock concentrated by nature.

H. M. A.

\section{THE UPPER AIR DURING FÖHN.}

$D$ R. H. VON FICKER has made notable additions to our knowledge of Föhn by his contributions on this subject to the Transactions of the Vienna Academy. His researches showed that the Alpine Föhn is the local manifestation of an extensive phenomenon which is revealed almost simultaneously in places of the same altitude over a large region. In a paper in the Sitzungsberichte of the Vienna Academy, May, I9.12, he describes observations on Föhn during three balloon ascents from Innsbruck in I9Io and I9II. It was found impossible to make ascents at the time of actual Föhn at the surface owing to the very gusty character of this wind. In one ascent only was the balloon over the mountains at the time of Föhn, and then it was the plaything of the vertical currents, which, however, were kind enough to spare the balloonists actual disaster. At one time the balloon was carried downwards $900 \mathrm{~m}$. and up again $1100 \mathrm{~m}$. in the course of five minutes, indicating vertical currents of five metres per second or more. Such information is clearly of importance to aviators, apart from its bearing on the elucidation of the meteorological phenomenon.

The general conclusions of von Ficker are that before the outbreak of Föhn at the surface, it is blowing over the cold air in the valleys and plains, the surface of separation between the two currents being frequently marked by strato-cumulus cloud. When the Föhn current crosses the ridges and valleys at right angles it descends on the lee side and ascends on the windward side, with a partial clearing of the cloud in the region of descending air. Föhn is usually dissipated by the coming of a north-west wind, the change probably being of the nature of a line-squall. The vertical temperature gradient during Föhn was ustially less than the adiabatic gradient for dry air, except when the balloon was carried up and down in the vertical currents, but it was greater than the normal gradient. The change of wind direction with altitude was normal, the south-east wind of the lower layers changing to south and south-west winds at higher levels up to $3-4 \mathrm{~km}$. The value of the discussion is enhanced by the results of ascents at Munich and observations at Zugspitze $(3000 \mathrm{~m}$.) which the author was able to incorporate by the courtesy of Dr. Schmauss, who is keenly enthusiastic about all upperair investigation.

E. GoLD. 